\title{
Hydrogen sulfide attenuates isoflurane- induced neuroapoptosis and cognitive impairment in the developing rat brain
}

\author{
Xueyuan Hu, Li Luan, Wei Guan, Shuai Zhang, Bei Li, Wei Ji and Honggang Fan* (D)
}

\begin{abstract}
Background: Isoflurane-induced neuroapoptosis and cognitive impairment has been previously reported. Hydrogen sulfide $\left(\mathrm{H}_{2} \mathrm{~S}\right)$ has been shown to be a neuromodulator that is thought to have anti-apoptotic, antiinflammatory, and anti-oxidative benefits. However, it is not known if $\mathrm{H}_{2} \mathrm{~S}$ is protective against anesthesia-induced apoptosis and cognitive defects.

Methods: In this study, postnatal day 7 (P7) Sprague-Dawley rats were randomly divided into four groups: control group (normal saline), $\mathrm{H}_{2} \mathrm{~S}$ group ( $\mathrm{NaHS} 28 \mu \mathrm{M} / \mathrm{kg}$ ), isoflurane group (normal saline $+0.75 \%$ isoflurane) and $\mathrm{H}_{2} \mathrm{~S}$ preconditioning group (NaHS $28 \mu \mathrm{M} / \mathrm{kg}+0.75 \%$ isoflurane). After exposure to isoflurane for $6 \mathrm{~h}$, half the numbers of rats in each group were euthanized, and the hippocampus and cerebral cortex were dissected and examined for apoptosis by the terminal deoxynucleotidyl transferase-mediated dUTP nick end-labeling (TUNEL) technique and western blot. After 6 weeks, the remaining rats were subjected to a Morris water maze (MWM) test for behavioral assessment.
\end{abstract}

Results: The TUNEL assay and western blot showed that when rats were preconditioned with NaHS, neuroapoptosis decreased significantly both in hippocampus and cerebral cortex compering with the isofulrane group. The MWM showed that P7 rats administration of NaHS improved cognitive impairments induced by isoflurane.

Conclusions: The current study demonstrates that $\mathrm{H}_{2} \mathrm{~S}$ attenuates isoflurane-induced neuroapoptosis and improves cognitive impairments in the developing rat brain.

Keywords: Hydrogen sulfide, Isoflurane, Neuroapoptosis, Cognitive impairment

\section{Background}

Isoflurane and other inhaled anesthetics are widely used on children for various types of surgeries. Although some studies have shown neuroprotection by anesthesia in in vitro and in vivo hypoxia/ischemia models [1, 2], numerous reports and some retrospective clinical studies have shown that inhaled anesthetics can induce apoptosis and can be detrimental to cognitive development [3-6], especially during the "brain growth spurt" stage, which occurs from P2 to P14 after birth in rodents [7]. Isoflurane modulates specific ligand-gated ion channels. It is principally an agonist for the $\gamma$-aminobutyric acid

\footnotetext{
* Correspondence: fanhonggang2002@163.com

Department of Veterinary Medicine, College of Veterinary Medicine,

Northeast Agricultural University, No. 600 of Changjiang Road, Xiangfang

District, Harbin, Heilongjiang Province, China
}

(GABA) type A receptor [8], thereby altering synaptic function [9]. Synaptic changes can result in long-term consequences for the developing brain, as was first identified with the deleterious effects of alcohol during neurodevelopment [10]. It has been reported that immature rats exposed to isoflurane have persistent memory and learning impairments, which are associated with widespread caspase-3 activation and neuronal apoptosis $[3,6,11]$.

Hydrogen sulfide $\left(\mathrm{H}_{2} \mathrm{~S}\right)$ is involved in many biological systems, and like nitric oxide and carbon monoxide, it is a signaling molecule in mammalian cells [12]. $\mathrm{H}_{2} \mathrm{~S}$ is widely recognized as a neuromodulator, and has been found at high levels in the hippocampus and cerebellum [13]. Exogenous $\mathrm{H}_{2} \mathrm{~S}$ donors have been used in many animal models to mimic the physiological and biological 
effects of endogenous $\mathrm{H}_{2} \mathrm{~S}$, which ranges in concentrations from $0.1 \mu \mathrm{M}$ to more than $300 \mu \mathrm{M}$ [14], although high concentrations of $\mathrm{H}_{2} \mathrm{~S}$ can detrimentally affect cytochrome oxidase in many tissues [15]. In the central nervous system, endogenous $\mathrm{H}_{2} \mathrm{~S}$ potentiates N-methyl$\mathrm{D}$-aspartate receptor-mediated currents and long-term potentiation (LTP), enhances the effect of GABA, regulates intracellular calcium levels, and stimulates uptake of synaptic glutamate by astrocytes [16, 17]. In addition, $\mathrm{H}_{2} \mathrm{~S}$-releasing drugs have been shown to affect a wide range of physiological responses, such as blood vessel relaxation [18], neurotransmission [13], regulation of inflammation [19], cardioprotection [20], and insulin release [21]. In light of their many physiological effects, several $\mathrm{H}_{2} \mathrm{~S}$ drugs are in clinical trials [22].

In recent years, researchers have demonstrated that xenon [23], dexmedetomidine [24] and isoflurane preconditioning [25] attenuate anesthesia-induced apoptosis and cognitive dysfunction in the developing rat brain. However, it has not been reported if $\mathrm{H}_{2} \mathrm{~S}$ can reduce anesthesia-induced apoptosis and cognitive defects. In this study we investigated if $\mathrm{NaHS}$ (a $\mathrm{H}_{2} \mathrm{~S}$ donor) could reduce neuronal injury and improve learning and memory caused by exposure to isoflurane at an early age. We feel that this study may offer new insights on treatments to help protect against neuroapoptosis and improve cognitive dysfunction caused by exposure to anesthetics.

\section{Methods}

\section{Animals}

Postnatal day 7 (P7) Sprague-Dawley rat pups of both sexes, weighing 16-18 g, provided by Harbin Medical University Experimental Animal Center. All experimental protocols were approved by the Animal Care and Use of Northeast Agricultural University Committee. Pups were housed in polypropylene cages, and allowed to reunite with their mothers after anesthesia. Rat were housed with $45 \%-55 \%$ humidity in 12-h light-dark cycle. Food and water were available freely and the room temperature was maintained at $22{ }^{\circ} \mathrm{C}-24{ }^{\circ} \mathrm{C}$.

\section{Anesthesia and treatment}

All rats were randomly assigned into four groups $(n=12)$ : a control group (Control $[\mathrm{CON}])$, a $\mathrm{H}_{2} \mathrm{~S}$ group (NaHS $\left.28 \mu \mathrm{M} / \mathrm{kg}\left[\mathrm{H}_{2} \mathrm{~S}\right]\right)$, an isoflurane group $(0.75 \%$ isoflurane [ISO]) and a $\mathrm{H}_{2} \mathrm{~S}$-treated group (NaHS $28 \mu \mathrm{M} / \mathrm{kg}+0.75 \%$ isoflurane $\left[\mathrm{H}_{2} \mathrm{~S}+\right.$ ISO $]$ ). Before (30 min prior) exposure to $0.75 \%$ isoflurane (Yipin Co., Ltd., Hebei, China), a single bolus of normal saline was injected intraperitoneally in rats in the CON and ISO groups. NaHS at $28 \mu \mathrm{M} / \mathrm{kg}$ doses was (Sigma-Aldrich, St Louis, MO, USA) injected intraperitoneally in the $\mathrm{H}_{2} \mathrm{~S}$ and $\mathrm{H}_{2} \mathrm{~S}+\mathrm{ISO}$ groups, respectively. Isoflurane was administered in an anesthesia chamber with $0.75 \%$ anesthetic mixed with $100 \%$ oxygen using an agent-specific vaporizer for ISO and $\mathrm{H}_{2} \mathrm{~S}+\mathrm{ISO}$ groups. Anesthesia was administered using a customized closed-circuit system, and carbon dioxide was eliminated with soda lime.

After $6 \mathrm{~h}$ exposure, half of the rat pups from each group were euthanized by intraperitoneal injection of pentobarbital sodium (150 mg/kg; Sigma, St. Louis, MO) overdose and the brains were dissected following an anatomical atlas as previously described [26]. Following decapitation, the left cerebral cortex and hippocampus of each brain were immediately frozen in liquid nitrogen and stored at $-80{ }^{\circ} \mathrm{C}$ for protein analysis. The contralateral side was post-fixed in $4 \%$ paraformaldehyde saline and kept at $4{ }^{\circ} \mathrm{C}$ for neuronal apoptosis analysis. The remaining animals were used for a behavioral study to determine their cognitive function after 6 weeks.

\section{TUNEL staining analyses}

After overnight fixation in $4 \%$ paraformaldehyde solution, the samples were embedded in paraffin blocks (5 $\mu \mathrm{m})$. Wax-embedded tissue sections were dewaxed and the brain sections were subjected to terminal deoxynucleotidyl transferase (TdT)-mediated dUTP nick endlabeling (TUNEL) using an Apop Tag plus peroxidase in situ kit (Keygen Biotechnology Co., Ltd., Nanjing, China). TUNEL staining shows DNA fragmentation and is recognized as a standard technique for the detection of apoptosis in tissue sections [27]. Following the manufacturer's instructions, paraffin blocks were immersed in $1 \%$ Triton X-100 (5 min, room temperature [RT]), 3\% $\mathrm{H}_{2} \mathrm{O}_{2}(10 \mathrm{~min}, \mathrm{RT}), 100 \mu \mathrm{l}$ proteinase $\mathrm{K}\left(30 \mathrm{~min}, 37^{\circ} \mathrm{C}\right)$, and $100 \mu \mathrm{l}$ DNase I reaction solution $\left(30 \mathrm{~min}, 37^{\circ} \mathrm{C}\right.$ ), then $50 \mu \mathrm{TdT}$ enzyme reaction solution (containing biotin-labeled dUTP, $60 \mathrm{~min}, 37^{\circ} \mathrm{C}$ ) and $50 \mu$ l horseradish peroxidase-conjugated streptavidin $\left(37^{\circ} \mathrm{C}\right)$ was added in sequence, and incubated in the dark. Tissue sections were treated with $3,3^{\prime}$-diaminobenzidine chromogen for approximately $5 \mathrm{~min}$ then counterstained with hematoxylin. For the control groups, sections were stained using the same procedures in the absence of DNase I and TdT reaction solutions. The numbers of TUNEL-positive cells were examined by an observer who was blind to the group assignment of the sections. Three sections were selected randomly from each sample and the numbers of positive cells (neurons) in the cerebral cortex and hippocampus were counted for each section at a high-magnification field $(\times 400)$ in five visual fields. The formula used for assessing apoptosis was apoptotic index $=$ the number of TUNEL-positive nuclei $\times 100 \% /$ the total number of nuclei.

\section{Western blot analyses}

Brain tissues were harvested and homogenized on ice before centrifugation at $13,000 \times \mathrm{g}$ at $4{ }^{\circ} \mathrm{C}$ for $5 \mathrm{~min}$. The 
supernatants were collected and saved at $-20{ }^{\circ} \mathrm{C}$. Total protein concentration was measured with the bicinchoninic acid method (Beyotime Biotechnology, Co., Ltd., Jiangsu, China). The samples were separated using $12 \%$ gel electrophoresis ( $90 \mathrm{~V}$ for $25 \mathrm{~min}$, then $120 \mathrm{~V}$ for $1 \mathrm{~h}$ ) and then transferred to a nitrocellulose membrane at $200 \mathrm{~mA}$ for $1 \mathrm{~h}$. The blots were blocked in 5\% milk Tris-buffered saline and Tween-20 (TBST) buffer for $1.5 \mathrm{~h}$ at $25{ }^{\circ} \mathrm{C}$, and then incubated with a monoclonal antibody against caspase-3 (1:1000; Cell Signaling Technology, Inc. \#9662, Danvers, MA, USA) or $\beta$-actin (1:1000; Cell Signaling Technology) in 5\% milk TBST buffer at $4{ }^{\circ} \mathrm{C}$ overnight. After washing in TBST, membranes were incubated with horseradish peroxidaseconjugated goat anti-rabbit IgG antibody (1:6000 dilution for $\beta$-actin and caspase-3, Wanleibio Co., Ltd., Shenyang, China) for $2 \mathrm{~h}$ at RT. Following the ECL reaction, the membranes were subjected to autoradiography and films were scanned using Tanon Imager 5200 software v2.03 (Tanon Co., Ltd., Shanghai, China). Western blot band intensity was quantified by the mean pixel intensity using Gel-Pro Analyzer 4 software (Media Cybernetics Inc., Bethesda, MD, USA).

\section{Learning and memory tests}

The Morris water maze (MWM) test has been described in multiple reviews to assess neural basis of allocentric learning and memory [28]. Briefly, as described previously [29], a round pool, $150 \mathrm{~cm}$ diameter and $50 \mathrm{~cm}$ depth, separated into quadrants, was filled with opaque water $\left(24{ }^{\circ} \mathrm{C}\right)$ to a height of $1.5 \mathrm{~cm}$ above the top of a movable clear $15-\mathrm{cm}$-diameter platform in a designated third quadrant. The pool was surrounded by a dark black curtain to prevent confounding visual cues. A video tracking system recorded the time it took the rats to reach the platform, and the data were analyzed using motion detection software for the MWM (Xinxin Software, Shanghai, China). The P42 rats were trained for 5 days to determine the ability of the rats to obtain spatial information. All rats were subjected to two trials per day in each of the four quadrants of the swimming pool. For each trial, rats were placed at a fixed position in the swimming pool, facing the wall, and allowed to search for the platform in the third quadrant for up to $90 \mathrm{~s}$. If a rat did not find the platform within $90 \mathrm{~s}$, the rat was gently guided to the platform and allowed to remain there for $20 \mathrm{~s}$. For all training trials, swimming speed and the time to reach the platform (escape latency time) were recorded. If a rat took less time to reach the platform, the learning ability was considered to be improved. We took the average time of two trials as the escape latency time in each day. After the 5-day training, probe trials were assessed immediately to evaluate memory retention capability. The probe trials involved removing the submerged platform in the third quadrant from the pool and allowing the rats to swim for $90 \mathrm{~s}$ in any of the four quadrants of the pool. The number of times the rats crossed the original platform position and the time they spent in the object quadrant were recorded. After every trial, each rat was wiped dry and kept warm before returning it to its cage.

\section{Statistical analysis}

GraphPad Prism 7 (GraphPad Software for Windows Inc., San Diego, CA, USA) was used for statistical analysis and graph generation. The average number of platform crossings were expressed as median and interquartile range and analyzed using the Mann-Whitney U test. The escape latency and other assessments were expressed as mean \pm standard deviation (SD) and determined by two-way repeated factor analysis of variance (ANOVA) with Student-Newman-Keuls or Bonferroni's tests. In all experiments, differences were considered statistically significant at $p<0.05$ and extremely significant at $p<0.01$.

\section{Results \\ $\mathrm{H}_{2} \mathrm{~S}$ mitigates neuronal apoptosis induced by $0.75 \%$ isoflurane}

No signs of abdominal pain or discomfort were observed after administration of NaHS or normal saline, and none of the rats died. After exposure to $0.75 \%$ isoflurane for $6 \mathrm{~h}$, TUNEL-positive cells were quantitated in all assessed brain samples (Fig. 1A), and compared with the CON group, neuronal apoptosis was higher (Fig. 1A: d, e, f) in both the hippocampus and cerebral cortex. However, the $\mathrm{H}_{2} \mathrm{~S}$-treated group showed neuro-protection, compared with the ISO group, with less nuclei shrinkage or broken or destroyed nuclei, especially in the hippocampal CA3 region and cerebral cortex (Fig. 1A: g, h, i, j, k, l). Quantification of apoptotic index (Fig. 1B) revealed that the number of TUNEL-positive cells increased significantly in the ISO group, compared with the CON group, in the cerebral cortex $(p<0.01)$ and in the hippocampus $(p<0.01)$. However, the number of TUNEL-positive cells in the $\mathrm{H}_{2} \mathrm{~S}$ treatment group was reduced significantly (cortex, $p<0.01$; hippocampus, $p<0.01$, vs the ISO group), although it was still greater than the CON group in both the cortex $(p<0.05)$. There was no significant differences between the $\mathrm{H}_{2} \mathrm{~S}$ group and $\mathrm{CON}$ group.

The present study also confirmed that exposure to $0.75 \%$ isoflurane for $6 \mathrm{~h}$ could induce caspase- 3 activation, as shown in Fig. 2, in both the hippocampus and cerebral cortex (both $p<0.01$, vs CON group), but the $\mathrm{H}_{2} \mathrm{~S}$ does not increased it. However, compared with the ISO group, the expression of cleaved caspase-3 decreased significantly in the $\mathrm{H}_{2} \mathrm{~S}+\mathrm{ISO}$ group, in both the 


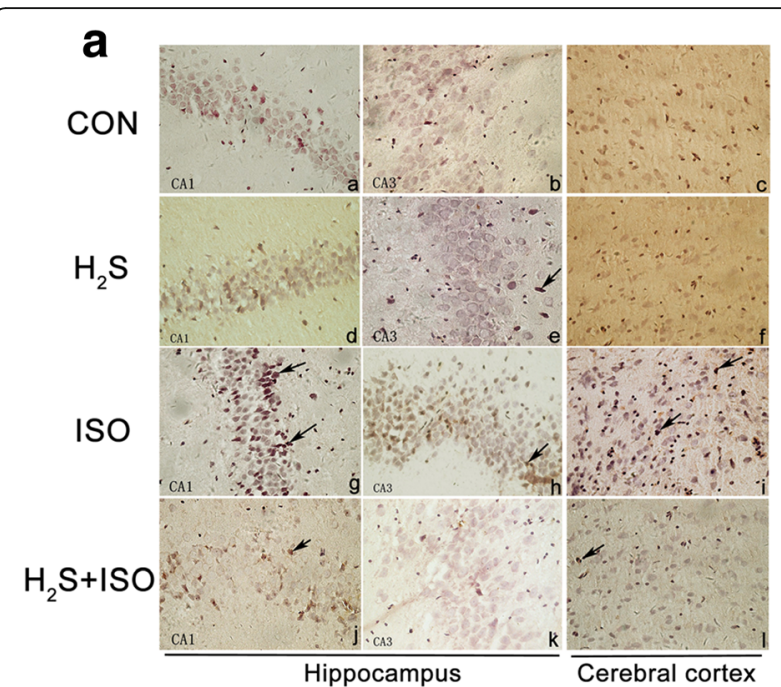

b

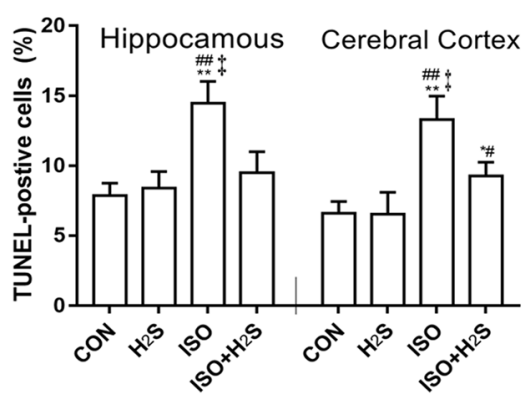

Fig. $1 \mathrm{H} 2 \mathrm{~S}$ attenuates isoflurane-induced neuro-apoptosis in hippocampus and cerebral cortex tissue. Paraffin sections were stained with the TUNEL technique using Apop Tag kit and counterstained with hematoxylin (A), under a high magnification (400x). For positive cells, nuclei stained dark brown with irregular or disintegration of different apoptotic bodies (indicated by the arrows); as for negative cells with nuclei light blue and regular. Quantification of apoptosis following TUNEL staining (B), calculating the apoptotic indices, expressed as Mean \pm SD of five $400 \times$ fields in each rat $(n=6) .{ }^{*} p<0.05,{ }^{* *} p<0.01$ presented a significant difference compared with CON group; \# $p<0.05$, \#\# $p<0.01$ presented a significant difference compared with $\mathrm{H}_{2} \mathrm{~S}$ group, $\neq p<0.01$ presented a significant difference between $\mathrm{ISO}$ group and $\mathrm{ISO}+\mathrm{H}_{2} \mathrm{~S}$ group

hippocampus $(p<0.01)$ and cerebral cortex $(p<0.01)$, even the cleaved caspase-3 levels in cerebral cortex was still higher in ISO $+\mathrm{H}_{2} \mathrm{~S}$ group than that in $\mathrm{CON}$ group $(p<0.05)$.

\section{$\mathrm{H}_{2} \mathrm{~S}$ improved cognitive impairment caused by exposure to $0.75 \%$ isoflurane}

The results from the escape latency trials to evaluate the abilities of the P42 rats for swimming and visual abilities in the MWM are summarized in Fig. 3a. Compared with the CON group, the average time to reach the submerged platform for the ISO group increased at P44, and P45 $(p<0.01, p<0.01$, respectively). And there was no different between $\mathrm{CON}$ group and $\mathrm{H}_{2} \mathrm{~S}$ group during the training days. Compared with the $\mathrm{H}_{2} \mathrm{~S}$ group, the average time to reach the submerged platform for the ISO group also increased at P44, and $\mathrm{P} 45(p<0.05, p<0.01$, respectively). In addition, the significant differences was also found between ISO group and ISO $+\mathrm{H}_{2} \mathrm{~S}$ group at $\mathrm{P} 44$ and $\mathrm{P} 45$ ( $p<0.01, p<0.01$, respectively). In the probe test, the rats in the ISO group spent less time in the third quadrant where the platform was located (Fig. 3b) than that in the other groups ( $p<0.01$ vs the CON group, $p<0.01$ vs the $\mathrm{H}_{2} \mathrm{~S}$ group and $p<0.05$ vs the ISO $+\mathrm{H}_{2} \mathrm{~S}$ group). The number of crossings over the missing platform location were fewer in the ISO group (Fig. 3c) compared with the CON $(p<0.05)$, the $\mathrm{H}_{2} \mathrm{~S}(p<0.05)$ and the ISO $+\mathrm{H}_{2} \mathrm{~S}$ group $((p<0.05)$. Furthermore, there were no significant differences in swim speed during the probe trials (data not shown).

\section{Discussion}

In the present study we demonstrated that exposure to $0.75 \%$ isoflurane for $6 \mathrm{~h}$ can significantly increase the level of activated caspase- 3 in the hippocampus and cortex of P7 rats, and cause long-term cognitive impairment when they reached adulthood. However, administration of NaHS (a $\mathrm{H}_{2} \mathrm{~S}$ donor) was found to decrease isoflurane-mediated neuroapoptosis and improve cognitive impairment.

Based on the British Journal of Anaesthesia, Salzburg Seminar, anesthesia neurotoxicity is influenced by many critical factors, such as the time and degree of the developing brain, the specific anesthetic drugs, the health status of the pups and specific procedure used for exposure to anesthetics [30]. The reason we chose the brain during the growth period is that it is susceptible to acute neural injuries, including by anesthetics. A previous study showed that P14 mice exposed to $1.7 \%$ isoflurane for 35 min daily for 4 successive days caused persistent, progressive memory dysfunction and reduced neurogenesis in young rodents, but not in P60 mice [31]. By contrast, $\mathrm{H}_{2} \mathrm{~S}$ in the central nervous system is thought to have anti-apoptotic, anti-inflammatory and antioxidative benefits in mouse models of ischemia/hypoxia, Alzheimer's disease and Parkinson's disease [32]. Thus, we felt that it would be therapeutically meaningful to investigate whether $\mathrm{H}_{2} \mathrm{~S}$ is beneficial against the neurotoxic effects of anesthetics such as neuroapoptosis and cognitive impairment.

Our data show that administration of NaHS decreased isoflurane-induced cleaved caspase- 3 levels, which is a well-established biomarker of apoptosis, in the developing rat brain. These results suggest that the mechanism for $\mathrm{H}_{2} \mathrm{~S}$-induced neuroprotection occurs via activation of intrinsic or extrinsic anti-apoptotic pathways. However, this still needs further investigation. Fortunately, some previous findings seem to support our results. For 


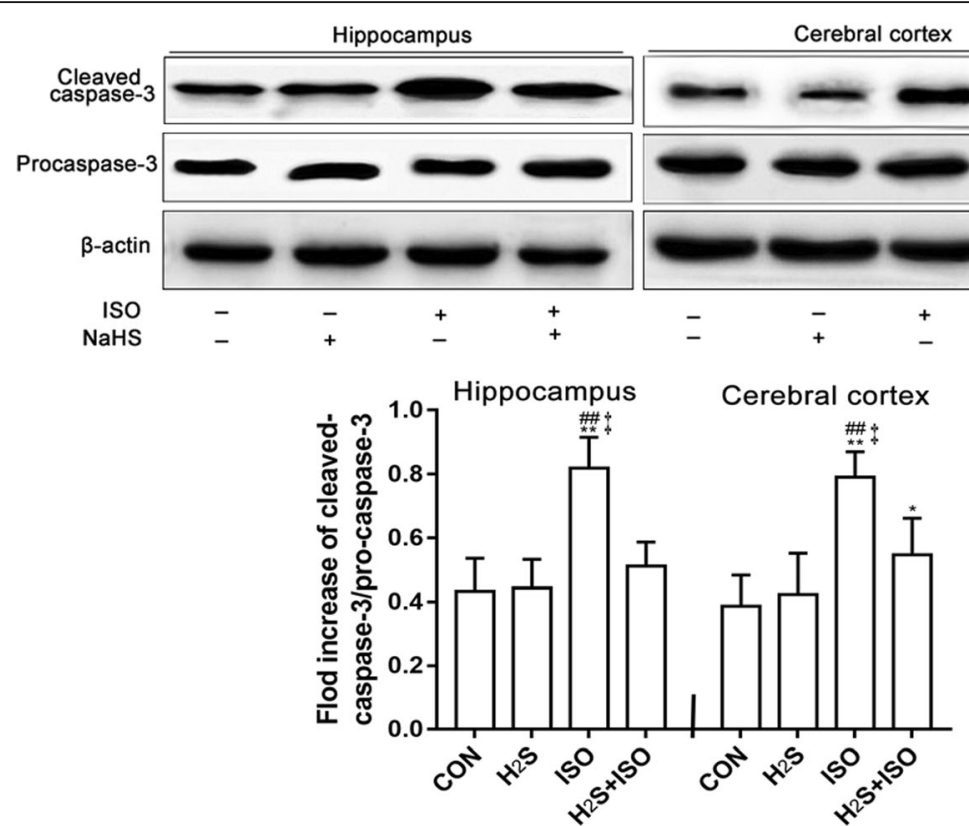

Fig. 2 H2S attenuates isoflurane-induced cleaved caspase-3 in hippocampus and cerebral cortex at an early age. Results are presented as the ratio of the intensity of the activation caspase-3 band to the intensity of the pro-caspase-3 band. Data are presented as the Mean \pm SD $(n=6) .{ }^{*} p<0.05$, ${ }^{* *} p<0.01$ presented a significant difference compared with CON group; \#\# $p<0.01$ presented a significant difference compared with $\mathrm{H}_{2} \mathrm{~S}$ group, $\neq p<0.01$ presented a significant difference between ISO group and $\mathrm{ISO}+\mathrm{H}_{2} \mathrm{~S}$ group

example, it has been reported that endogenous $\mathrm{H}_{2} \mathrm{~S}$ is a neuromodulator and it can mediate membrane ion channels, such as ATP-sensitive potassium $\left(\mathrm{K}_{\mathrm{ATP}}\right)$ channel and voltage-dependent calcium channels (VDCCs). The activation of $\mathrm{K}_{\mathrm{ATP}}$ would hyperpolarization of neurons, reduce abnormal excitatory synaptic activity and are neuroprotective [33]. $\mathrm{H}_{2} \mathrm{~S}$ can also indirectly inhibits Ltype VDCCs currents in isolated mouse pancreatic $\beta$ cells [34] and rat cardiomyocytes [35], even another study in cerebellar granule neurons reported that $\mathrm{H}_{2} \mathrm{~S}$ increased intracellular calcium ion concentration by stimulating L-type VDCCs [36]. Moreover, it can potentiate the effect of GABA and regulate stimulation of synaptic glutamate by astrocytes [37]. Interestingly, isoflurane can enhance and open $\mathrm{GABA}_{\mathrm{A}}$ receptor channels directly [38] and open VDCCs. This increases intracellular calcium ion concentrations, which promote the activation of caspase-3 [11] or activate the mitochondrial apoptosis pathway [39]. Evidence demonstrate that $\mathrm{H}_{2} \mathrm{~S}$ had anti-apoptotic effects via inhibition the forming and opening of mitochondrial permeability transition pores and the subsequent release of cytochrome $\mathrm{C}$ from mitochondria to the cytosol, as well as the activation of the caspase cascades [40]. $\mathrm{H}_{2} \mathrm{~S}$ could protect neurons from oxidative stress via scavenging of reactive oxygen and/or nitrogen species (ROS and RNS) [41] and increasing production of glutathione which is a major and potent intracellular antioxidant [42]. $\mathrm{H}_{2} \mathrm{~S}$ may also upregulate endogenous antioxidants through a nuclear-factor- E2- related factor-2 (Nrf2) dependent signaling pathway [43]. Evidence also finding $\mathrm{H}_{2} \mathrm{~S}$ may stimulate glutamate transport function to protect brain from oxidative stress [44]. On the contrary, many anesthetics, even under normoxic conditions, can increase ROS, which cause neuronal lipid peroxidation and neuronal death in vulnerable brain regions such as the subiculum in the hippocampus [45]. $\mathrm{H}_{2} \mathrm{~S}$ can also regulation intracellular signaling pathway to inhibit neuronal apoptosis. It can inhibits rotenone induced apoptosis via regulation of p38- and JNK-MAPK signaling pathway [40] and suppress $\mathrm{H}_{2} \mathrm{O}_{2}$-induced ERK $1 / 2$ activation in primary cultured astrocytes [44]. $\mathrm{H}_{2} \mathrm{~S}$ also acted via cAMP-mediated PI3K/Akt/p70S6K signal transduction pathways to inhibit hippocampal neuronal apoptosis and protect neurons from oxygen glucose deprivation/reoxygenation induced injury [46]. $\mathrm{H}_{2} \mathrm{~S}$ also downregulates cytokines, such as tumor necrosis factor- $\alpha$ and interleukin- 6 [47]. However, it has been found that clinically relevant isoflurane levels can increase the levels of tumor necrosis factor- $\alpha$, interleukin- 6 , and interleukin- $1 \beta$ and thus may cause neuro-inflammation [48]. However, further research is needed to determine how $\mathrm{H}_{2} \mathrm{~S}$ is neuroprotective. As mentioned before, $\mathrm{H}_{2} \mathrm{~S}$ donors have shown beneficial therapeutic effects in neurodegenerative disease models. Some research also found that the brain levels of $\mathrm{H}_{2} \mathrm{~S}$ in Alzheimer's disease are lower than age-matched healthy controls [49], and that $\mathrm{H}_{2} \mathrm{~S}$ attenuates deficits in cognition induced by ischemic stroke and surgical trauma [50,51]. 

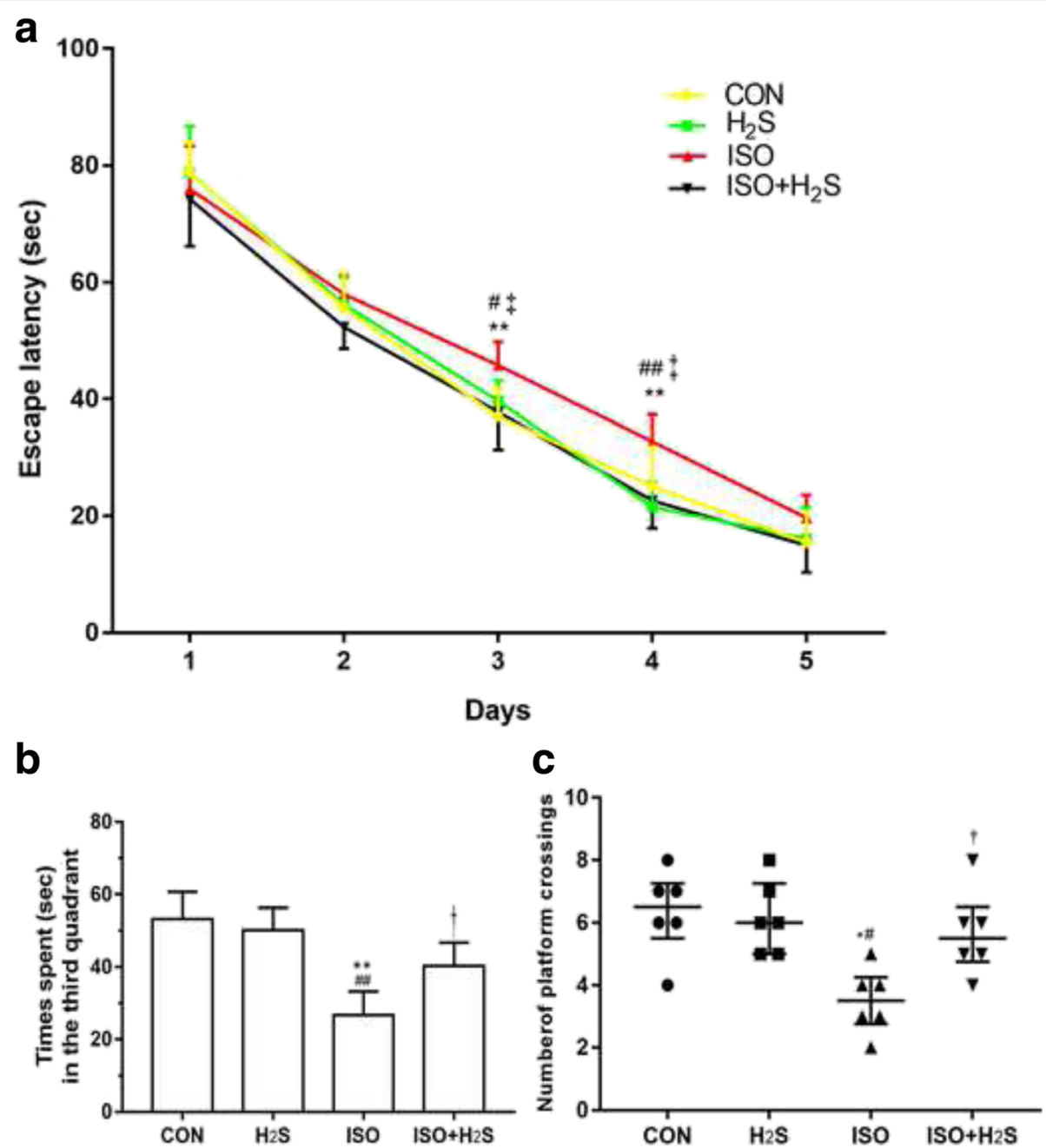

Fig. $3 \mathrm{H} 2 \mathrm{~S}$ attenuates isoflurane-induced cognitive impairments in the developing brain. Place trial demonstrating the latency time for the rats to arrive at the platform measuring spatial information acquisition (a). Probe trial demonstrating the time spent in the target (the third) quadrant (b) and the number of original platform crossings (c) measuring memory retention capabilities. Data represent as Mean \pm SD $(n=6)$ in $\mathbf{a}$ and $\mathbf{b}$, as median and interquartile range in $\mathbf{c} .{ }^{*} p<0.05,{ }^{* *} p<0.01$ presented a significant difference compared with CON group; \#p<0.05, \#\# $p<0.01$ presented a significant difference compared with $\mathrm{H}_{2} \mathrm{~S}$ group, $\uparrow p<0.05, \neq p<0.01$ presented a significant difference between ISO group and $\mathrm{ISO}+\mathrm{H}_{2} \mathrm{~S}$ group

Therefore, $\mathrm{H}_{2} \mathrm{~S}$ may be beneficial for extended use of anesthetics in maintaining long-term neurocognition. There are some reports on the causal link between anesthesiainduced neuroapoptosis and anesthesia-induced cognitive impairment. Studies have shown neuronal loss and perturbation of synaptic proteins are linked to cognitive ability [52], and neurogenesis is thought to play an important role in memory and learning in the hippocampus. Thus excessive apoptosis can affect the development of the central nervous system and even affect its physiological function [53]. In our study, the reduction of neuroapoptosis correlated with more pronounced memory impairment. The neural mechanisms of learning and memory depend not only on the structural plasticity of the central nervous system but also on the integrity of the neural network. Therefore, neuroapoptosis may affect the integrity of the neural network, thus impairing learning and memory [54, 55]. Our data suggest that reduced neuroapoptosis during brain development is important for cognitive development. However, Zhu et al. showed that P14 rats exposed to isoflurane for 4 consecutive days ( $35 \mathrm{~min}$ a day) did not have increased numbers of TUNEL-positive cells and active caspase- 9 compared with the control group, or changes in synapsin I density, but did have impairment in reversal learning in rats [31]. These findings suggest some unknown mechanism of neurotoxicity by inhalation anesthetics, which cause cognitive deficits or cell death. 
There were some limitations to our study. Although we found an effect of exogenous hydrogen sulfide on isoflurane-induced apoptosis and cognitive impairment in P7 rats, we did not delve into the mechanism of neuroprotection by $\mathrm{H}_{2} \mathrm{~S}$. However, several studies have demonstrated different signaling pathways of protection by $\mathrm{H}_{2} \mathrm{~S}$ [56]. Therefore, in our next study we will explore the mechanism of neuroprotection by $\mathrm{H}_{2} \mathrm{~S}$, such as testing its effect on LTP on isoflurane-treated hippocampal slices.

\section{Conclusions}

In conclusion, the present study shows that administration of $\mathrm{H}_{2} \mathrm{~S}$ reduces neuroapoptosis and improves cognitive impairment caused by clinically relevant levels of isoflurane for $6 \mathrm{~h}$ in the developing rat brain. But further studies are needed to determine how $\mathrm{H}_{2} \mathrm{~S}$ protects against anesthesia-induced apoptosis.

\begin{abstract}
Abbreviations
ANOVA: Analysis of variance; GABA: $\gamma$-aminobutyric acid; $\mathrm{H}_{2} \mathrm{~S}$ : Hydrogen sulfide; $\mathrm{K}_{\text {ATP }}$ : ATP-sensitive potassium channel; LTP: Long-term potentiation; MWM: Morris water maze; Nrf2: Nuclear-factor- E2-related factor-2; ROS/ RNS: Reactive oxygen and/or nitrogen species; RT: Room temperature; SD: Standard deviation; TBST: Tris-buffered saline and Tween-20; TUNEL: Terminal deoxynucleotidyl transferase-mediated dUTP nick endlabeling; VDCCs: Voltage-dependent calcium channels
\end{abstract}

\section{Acknowledgements}

Not applicable.

\section{Funding}

This work was supported by China Postdoctoral Science Foundation of Heilongjiang Province (LBH-Q14018) and "Academic Backbone" Project of Northeast Agricultural University (15XG18).

\section{Availability of data and materials}

The datasets generated and analyzed during the current study are available from the corresponding author on reasonable request.

\section{Authors' contributions}

HXY and FHG helped to design the study, analyze the data and write the manuscript. LL, GW and ZS analyzed the data and drafted the manuscript. $\mathrm{ZS}, \mathrm{LB}$ and JW performed the experiments and analyzed the data. All authors have read and approved the final manuscript.

\section{Ethics approval and consent to participate}

All experimental protocols were approved by the Animal Care and Use of Northeast Agricultural University Committee.

\section{Consent for publication}

Not Applicable.

\section{Competing interests}

The authors declare that they have no conflict of interest.

\section{Publisher's Note}

Springer Nature remains neutral with regard to jurisdictional claims in published maps and institutional affiliations.
Received: 18 February 2017 Accepted: 27 August 2017

Published online: 05 September 2017

\section{References}

1. Sakai $H$, Sheng $H$, Yates RB, Ishida K, Pearlstein RD, Warner DS. Isoflurane provides long-term protection against focal cerebral ischemia in the rat. Anesthesiology. 2007;106(1):92-9. discussion 98-10

2. Popovic R, Liniger R, Bickler PE. Anesthetics and mild hypothermia similarly prevent hippocampal neuron death in an in vitro model of cerebral ischemia. Anesthesiology. 2000;92(5):1343-9.

3. Yon J-H, Daniel-Johnson J, Carter L, Jevtovic-Todorovic V. Anesthesia induces neuronal cell death in the developing rat brain via the intrinsic and extrinsic apoptotic pathways. Neuroscience. 2005;135(3):815-27.

4. Cattano D, Williamson P, Fukui K, Avidan M, Evers AS, Olney JW, Young C. Potential of xenon to induce or to protect against neuroapoptosis in the developing mouse brain. Can J Anaesth. 2008;55(7):429-36.

5. Yang B, Liang G, Khojasteh S, Wu Z, Yang W, Joseph D, Wei H. Comparison of neurodegeneration and cognitive impairment in neonatal mice exposed to propofol or isoflurane. PLoS One. 2014;9(6):e99171.

6. Jevtovic-Todorovic V, Hartman RE, Izumi Y, Benshoff ND, Dikranian K, Zorumski CF, Olney JW, Wozniak DF. Early exposure to common anesthetic agents causes widespread neurodegeneration in the developing rat brain and persistent learning deficits. J Neurosci. 2003;23(3):876-82.

7. Dobbing J, Sands J. Comparative aspects of the brain growth spurt. Early Hum Dev. 1979;3(1):79-83.

8. Grasshoff C, Rudolph U, Antkowiak B. Molecular and systemic mechanisms of general anaesthesia: the 'multi-site and multiple mechanisms' concept. Curr Opin Anaesthesiol. 2005;18(4):386-91.

9. Franks NP. Molecular targets underlying general anaesthesia. Br J Pharmacol. 2006;147(Suppl 1):S72-81.

10. Ikonomidou C, Bittigau P, Ishimaru MJ, Wozniak DF, Koch C, Genz K, Price MT, Stefovska V, Horster F, Tenkova T, et al. Ethanol-induced apoptotic neurodegeneration and fetal alcohol syndrome. Science. 2000;287(5455):1056-60.

11. Zhang G, Dong Y, Zhang B, Ichinose F, Wu X, Culley DJ, Crosby G, Tanzi RE, Xie Z. Isoflurane-induced caspase-3 activation is dependent on cytosolic calcium and can be attenuated by memantine. J Neurosci. 2008;28(17):4551-60.

12. Kimura $H$, Shibuya $N$, Kimura $Y$. Hydrogen sulfide is a signaling molecule and a cytoprotectant. Antioxid Redox Signal. 2012;17(1):45-57.

13. Abe $\mathrm{K}$, Kimura $\mathrm{H}$. The possible role of hydrogen sulfide as an endogenous neuromodulator. J Neurosci. 1996;16(3):1066-71.

14. McCook O, Radermacher $P$, Volani C, Asfar P, Ignatius A, Kemmler J, Moller P, Szabo C, Whiteman M, Wood ME, et al. H2S during circulatory shock: some unresolved questions. Nitric Oxide. 2014;41:48-61.

15. Dorman DC, Moulin FJ, McManus BE, Mahle KC, James RA, Struve MF. Cytochrome oxidase inhibition induced by acute hydrogen sulfide inhalation: correlation with tissue sulfide concentrations in the rat brain, liver, lung, and nasal epithelium. Toxicol Sci. 2002;65(1):18-25.

16. Hu LF, Lu M, Hon Wong PT, Bian JS. Hydrogen sulfide: neurophysiology and neuropathology. Antioxid Redox Signal. 2011;15(2):405-19.

17. Zhou CF, Tang XQ. Hydrogen sulfide and nervous system regulation. Chin Med J. 2011;124(21):3576-82.

18. Ali MY, Ping CY, Mok YY, Ling L, Whiteman M, Bhatia M, Moore PK. Regulation of vascular nitric oxide in vitro and in vivo; a new role for endogenous hydrogen sulphide? Br J Pharmacol. 2006;149(6):625-34.

19. Hu LF, Wong PT, Moore PK, Bian JS. Hydrogen sulfide attenuates lipopolysaccharide-induced inflammation by inhibition of p38 mitogen-activated protein kinase in microglia. J Neurochem. 2007:100(4):1121-8.

20. Johansen D, Ytrehus K, Baxter GF. Exogenous hydrogen sulfide (H2S) protects against regional myocardial ischemia-reperfusion injury-evidence for a role of K ATP channels. Basic Res Cardiol. 2006;101(1):53-60.

21. Ali MY, Whiteman M, Low CM, Moore PK. Hydrogen sulphide reduces insulin secretion from HIT-T15 cells by a KATP channel-dependent pathway. J Endocrinol. 2007;195(1):105-12.

22. Wallace $J$ L, Wang R. Hydrogen sulfide-based therapeutics: exploiting a unique but ubiquitous gasotransmitter. Nat Rev Drug Discov. 2015;14(5):329-45.

23. Ma D, Williamson $P$, Januszewski $A$, et al. Xenon mitigates isofluraneinduced neuronal apoptosis in the developing rodent brain[J]. 
Anesthesiology: The Journal of the American Society of Anesthesiologists. 2007;106(4):746-53.

24. Robert D, Sanders BS. Dexmedetomidine attenuates isoflurane-induced neurocognitive impairment in neonatal rats.Pdf. Anesthesiology. 2009;1 10:1077-85

25. Peng J, Drobish JK, Liang G, Wu Z, Liu C, Joseph DJ, Abdou H, Eckenhoff MF, Wei $\mathrm{H}$. Anesthetic preconditioning inhibits isoflurane-mediated apoptosis in the developing rat brain. Anesth Analg. 2014;119(4):939-46.

26. Paxinos $\mathrm{G}$, Watson $\mathrm{C}$, Petrides $\mathrm{M}$, et al. The marmoset brain in stereotaxic coordinates[M]. San Diego: Elsevier Academic Press; 2012.

27. Ansari B, Coates PJ, Greenstein BD, Hall PA. Situ end-labelling detects DNA strand breaks in apoptosis and other physiological and pathological states. J Pathol. 1993;170(1):1-8

28. Vorhees CV, Williams MT. Value of water mazes for assessing spatial and egocentric learning and memory in rodent basic research and regulatory studies. Neurotoxicol Teratol. 2014;45:75-90.

29. Liang G, Ward C, Peng J, Zhao Y, Huang B, Wei H. Isoflurane causes greater neurodegeneration than an equivalent exposure of sevoflurane in the developing brain of neonatal mice. Anesthesiology. 2010;112(6):1325.

30. Jevtovic-Todorovic V, Absalom AR, Blomgren K, Brambrink A, Crosby G, Culley DJ, Fiskum G, Giffard RG, Herold KF, Loepke AW, et al. Anaesthetic neurotoxicity and neuroplasticity: an expert group report and statement based on the BJA Salzburg seminar. Br J Anaesth. 2013;111(2):143-51.

31. Zhu C, Gao J, Karlsson N, Li Q, Zhang Y, Huang Z, Li H, Kuhn HG, Blomgren K. Isoflurane anesthesia induced persistent, progressive memory impairment, caused a loss of neural stem cells, and reduced neurogenesis in young, but not adult, rodents. J Cereb Blood Flow Metab. 2010;30(5):1017-30.

32. Jin Z, Chan H, Ning J, Lu K, Ma D. The role of hydrogen sulfide in pathologies of the vital organs and its clinical application. J Physiol Pharmacol. 2015;66(2):169-79.

33. Kimura $Y$, Dargusch $R$, Schubert D, Kimura H. Hydrogen sulfide protects HT22 neuronal cells from oxidative stress. Antioxid Redox Signal. 2006;8(3-4):661-70

34. Tang G, Zhang L, Yang G, Wu L, Wang R. Hydrogen sulfide-induced inhibition of L-type Ca2+ channels and insulin secretion in mouse pancreatic beta cells. Diabetologia. 2013;56(3):533-41.

35. Zhang R, Sun Y, Tsai H, Tang C, Jin H, Du J. Hydrogen sulfide inhibits L-type calcium currents depending upon the protein sulfhydryl state in rat cardiomyocytes. PLoS One. 2012;7(5):e37073.

36. Garcia-Bereguiain MA, Samhan-Arias AK, Martin-Romero FJ, Gutierrez-Merino C. Hydrogen sulfide raises cytosolic calcium in neurons through activation of L-type Ca2+ channels. Antioxid Redox Signal. 2008;10(1):31-42.

37. Zhou ZW, Shu Y, Li M, Guo X, Pac-Soo C, Maze M, Ma D. The glutaminergic, GABAergic, dopaminergic but not cholinergic neurons are susceptible to anaesthesia-induced cell death in the rat developing brain. Neuroscience. 2011:174:64-70

38. Raines DE, Claycomb RJ, Forman SA. Modulation of GABA(A) receptor function by nonhalogenated alkane anesthetics: the effects on agonist enhancement, direct activation, and inhibition. Anesth Analg. 2003:96(1):112-8. table of contents

39. Zhang Y, Dong Y, Wu X, Lu Y, Xu Z, Knapp A, Yue Y, Xu T, Xie Z. The mitochondrial pathway of anesthetic isoflurane-induced apoptosis. J Biol Chem. 2010;285(6):4025-37

40. Hu LF, Lu M, Z-Y W, Wong PT-H, Bian J-S. Hydrogen sulfide inhibits rotenone-induced apoptosis via preservation of mitochondrial function. Mol Pharmacol. 2009;75(1):27-34.

41. Łowicka E, Beltowski J. Hydrogen sulfide (H2S)-the third gas of interest for pharmacologists. Pharmacol Rep. 2006;59(1):4-24.

42. Kimura Y, Goto Y-I, Kimura H. Hydrogen sulfide increases glutathione production and suppresses oxidative stress in mitochondria. Antioxid Redox Signal. 2010;12(1):1-13

43. Calvert JW, Jha S, Gundewar S, Elrod JW, Ramachandran A, Pattillo CB, Kevil CG, Lefer DJ. Hydrogen sulfide mediates cardioprotection through Nrf2 signaling. Circ Res. 2009;105(4):365-74.

44. Lu M, L-F H, Hu G, Bian J-S. Hydrogen sulfide protects astrocytes against $\mathrm{H} 2$ $\mathrm{O}$ 2-induced neural injury via enhancing glutamate uptake. Free Radic Biol Med. 2008:45(12):1705-13.

45. Boscolo A, Starr JA, Sanchez V, Lunardi N, DiGruccio MR, Ori C, Erisir A, Trimmer P, Bennett J, Jevtovic-Todorovic $\mathrm{V}$. The abolishment of anesthesiainduced cognitive impairment by timely protection of mitochondria in the developing rat brain: the importance of free oxygen radicals and mitochondrial integrity. Neurobiol Dis. 2012;45(3):1031-41.

46. Shao J-L, Wan X-H, Chen Y, Bi C, Chen H-M, Zhong Y, Heng X-H, Qian J-Q. $\mathrm{H} 2 \mathrm{~S}$ protects hippocampal neurons from anoxia-reoxygenation through cAMP-mediated PI3K/Akt/p70S6K cell-survival signaling pathways. J Mol Neurosci. 2011;43(3):453-60.

47. Giuliani D, Ottani A, Zaffe D, Galantucci M, Strinati F, Lodi R, Guarini S. Hydrogen sulfide slows down progression of experimental Alzheimer's disease by targeting multiple pathophysiological mechanisms. Neurobiol Learn Mem. 2013;104:82-91.

48. Wu X, Lu Y, Dong Y, Zhang G, Zhang Y, Xu Z, Culley DJ, Crosby G, Marcantonio ER, Tanzi RE. The inhalation anesthetic isoflurane increases levels of proinflammatory TNF-a, IL-6, and IL-1 $\beta$. Neurobiol Aging. 2012;33(7):1364-78.

49. Eto K, Asada T, Arima K, Makifuchi T, Kimura H. Brain hydrogen sulfide is severely decreased in Alzheimer's disease. Biochem Biophys Res Commun. 2002;293(5):1485-8.

50. Wen X, Qi D, Sun Y, Huang X, Zhang F, Wu J, Fu Y, Ma K, Du Y, Dong H, et al. $H(2) S$ attenuates cognitive deficits through Akt1/JNK3 signaling pathway in ischemic stroke. Behav Brain Res. 2014;269:6-14.

51. Chu QJ, He L, Zhang W, Liu CL, Ai YQ, Zhang Q. Hydrogen sulfide attenuates surgical trauma-induced inflammatory response and cognitive deficits in mice. J Surg Res. 2013;183(1):330-6.

52. Fournier NM, Calverley KL, Wagner JP, Poock JL, Crossley M. Impaired social cognition 30 years after hemispherectomy for intractable epilepsy: the importance of the right hemisphere in complex social functioning. Epilepsy Behav. 2008;12(3):460-71.

53. Kuan CY, Roth KA, Flavell RA, Rakic P. Mechanisms of programmed cell death in the developing brain. Trends Neurosci. 2000;23(7):291-7.

54. Olney JW, Tenkova T, Dikranian K, Muglia LJ, Jermakowicz WJ, D'Sa C, Roth KA. Ethanol-induced caspase-3 activation in the in vivo developing mouse brain. Neurobiol Dis. 2002;9(2):205-19.

55. Arkhipov V. Memory dissociation: the approach to the study of retrieval processes. Behav Brain Res. 1999;106(1):39-46.

56. Nagpure BV, Bian JS. Brain, learning, and memory: role of $\mathrm{H} 2 \mathrm{~S}$ in neurodegenerative diseases. Handb Exp Pharmacol. 2015;230:193-215.

\section{Submit your next manuscript to BioMed Central and we will help you at every step:}

- We accept pre-submission inquiries

- Our selector tool helps you to find the most relevant journal

- We provide round the clock customer support

- Convenient online submission

- Thorough peer review

- Inclusion in PubMed and all major indexing services

- Maximum visibility for your research

Submit your manuscript at www.biomedcentral.com/submit
Biomed Central 